\title{
Key Drivers of Digitalization; EU Context and Baltic Case
}

\author{
Girts KARNITIS $^{1}$, Andris VIRTMANIS ${ }^{2,3}$, Edvins KARNITIS ${ }^{1,4}$ \\ ${ }^{1}$ University of Latvia, Faculty of Computing, Riga, Latvia \\ 2 Riga Technical University, Faculty of Electronics and Telecommunications, Riga, Latvia \\ 3 Public Utilities Commission, Riga, Latvia \\ 4 Cross-sectoral Coordination Centre, Riga, Latvia \\ girts.karnitiselu.lv, andris.virtmanisesprk.gov.lv, \\ edvins.karnitis@pkc.mk.gov.lv
}

\begin{abstract}
The integrated Digital Economy and Society Index (DESI) is calculated to indicate "progress of EU countries towards a digital economy and society"; nevertheless there are serious barriers to practical use of the DESI. The methodology of the DESI does not apply to development indicators; the natural doubts are on significance of more than 30 aspects for socioeconomic growth. The study propose the methodology for determination of the key drivers of digitalisation, hence areas of priority investments, which can provide the most dynamic socioeconomic progress as well as return of investments. The intelligent data mining and mathematical modelling methods and tools have been used to achieve a conclusion - only six aspects actually are significant for socioeconomic growth. Results are applicable to all EU member states; any economy would use them for strategic investments planning. Current strengths and weaknesses of the Baltic States are analysed in more detail and recommendations are elaborated.
\end{abstract}

Keywords: digitalization, socioeconomic growth, data mining, linear regression, mathematical models

\section{Introduction}

Advanced digital technologies enable new methods and lower costs of processing, storing, sharing, and analysing business information thus optimizing any activity and/or transaction. The European Commission (EC) regards ongoing comprehensive digitalization, new innovative economic models, so called digital economy as "the power to transform human societies and economies, with long-term benefits for both the economic growth and quality of life" (WEB, g). Very similar is OECD position, defining the digital transformation as a powerful tool to create the economic growth, to achieve more inclusive and sustainable prosperity and benefits for all (WEB, i).

Increasing part of economic and business processes currently is driven by digital technologies. "Digital economics explores how standard economic models change as certain costs fall substantially and perhaps approach zero" (Goldfarb et al., 2017). The digital economy might already be delivering minimum $20 \%$ of the global GDP; the European digital economy is growing 7 times as fast as the rest of the economy (WEB, b). 
Provision of punctual and reliable statistical information on digital transformation is fully understandable necessity to manage the process on national and EU scale; the EC framework document $(\mathrm{WEB}, \mathrm{h})$ updates principles and practice of the data collection and exploitation. The composite Digital Economy and Society Index (DESI) is calculated since 2014 as an annual analytical and benchmarking tool that "summarizes relevant indicators on Europe's digital performance and tracks the evolution of EU Member States in digital competitiveness" (WEB, c). The index integrates indices on penetration of and access to broadband (BB), digital skills, business and private activities in use of various digital services. The purpose is to indicate "progress of EU countries towards a digital economy and society" (WEB, c) and to determinate areas where the digital performance of the specific EU country could be improved by the priority investments and actions.

Nevertheless the evaluated digital performance and digital competitiveness of the country actually doesn't reflect impact of the digitalization on the growth of economy that is the defined final goal; methodology of the DESI does not apply to the economic indicators. It is a significant shortage of the DESI.

Large number of the component indicators (a total 31 indicators that are grouped in 5 functional clusters/dimensions and 12 sub-dimensions) provides a comprehensive and representative view on digitalization; on the other hand it considerably complicates the reasonable prioritizing of aspects that provide the strongest impact on growth, aspects where primary purposeful public and private investments will generate higher returns, i.e. an acceleration of the growth caused by digitalization. For many EU countries (including the Baltic States) the prioritization is an essential factor; for the time being, they are not able to invest immediately and simultaneously in all aspects (see more in (Karnitis et al., 2017) on economic gap between currently more successful Northern Europe and catching up Southern and Eastern Europe).

It is important to understand the digital aspects as well as their combination that is decisive for the economic growth: "neither broadband policies nor broadband penetration by themselves suffice to positively impact economic growth and there is a need for complementary growth drivers through which such broadband penetration influences growth" (Ghosh et al. 8, 2017). The main objectives of this study are:

- to determine the key digital drivers, hence areas of priority investments, which can best improve productivity and provide the most dynamic economic progress as well as return of investments;

- to determine optimal drivers' combination (Knickrehm et al., 2016) and to develop a quantitative model of the impact of digitalisation on the EU economies that can be used for modelling of the economic growth.

\section{Methodology}

A natural strategy of our study includes maximum usage of advantages of existing data sets (indexes) that are composed by experts. Presumably the key digital drivers for our model first and foremost should be selected from these data sets. 
The DESI statistics is available for 4 years (2014-2017) (WEB, c). This representative data set definitely would serve as an appropriate basis for analyzing and comparing digital performance aspects of the EU countries in relation to the economic and social growth.

The data set of ITU's ICT Development Index (IDI) (WEB, e), which integrates 11 indicators, would be another functionally similar option. The principal difference among them is the global coverage of the IDI (176 countries in 2017); the data set of the IDI should be considered as one that preserves support for the developing economies too. Some indicators are not actual for the highly developed EU economies (e.g., fixedtelephone subscriptions, Internet access, secondary gross enrolment ratio); at the same time prevalence rates of advanced applications are not included in the data set.

Similarly 29 indicators are aggregated to assess the score of the data innovation in EU countries (Wallace et al., 2017); the DESI statistics is widely used. Nevertheless this score is a one-off study that significantly decreases the reliability of evaluation. Therefore we chose the DESI data set as an input point for data mining and modelling.

The intelligent data mining methods are appropriate for discovery of and knowledge creation on existing regularities in the data set, which relates to the economic and social growth. The benchmarking data mining algorithms are well suited to investigate cause and effect relationships and to compare the digital performance aspects of countries, to discover the top performing leaders and to identify the best practices, to analyze how higher performance level is achieved and how currently less successful and lagging behind countries could progress faster. "The challenges in such a benchmarking exercise are manifold, in the selection of a representative set of indicators measuring the complex content of technology development ... and in the integration of the results of benchmarking into policy analysis. ... Comparison with better-performing countries helps identify policies for further improvement and progression" (Haqqani, 2005).

On the other hand the usage of mathematical modelling tools has become popular and generally accepted method for the prediction of the scenarios in a wide variety of fields from a general state management (e.g., (Bicevskis et al., 2014)) to the specific sectoral issues (e.g., (Sarma et al., 2017)( Zuters et al., 2016)). In our case the modelling will determine the exact relationships between the digital indicators as independent variables and some growth indicator as the dependent (target) variable, which should reflect the economic performance and social progress in the corresponding country (Karnitis et al., 2017). This way we will disclose the impact of digital indicators on growth and extract the most significant ones (key performance indicators (KPI)) reducing a large number of potential drivers. To perform the modelling, a dependent (target) variable, which reflects the progress, should be determined.

The digitalization doesn't change the fundamental paradigm of economy as the space and the set of activities related to the making, trading and consumption of goods and services; "the whole purpose of the digital economy mantra is to urge economies, sectors and companies to innovate in order to sustain or bring forth more welfare" (Wammerdam, 2014).

Among the interrelated major macroeconomic indices (productivity, competitiveness, investments, national income, etc.) the gross domestic product (GDP) is politically accepted key economic indicator for any country. A criticism of some GDP shortcomings (related to income distribution, informal economy, in the last years also to digitalization of economy (Quiggin, 2014)) is not a secret; nevertheless the GDP has maintained its position as the most commonly used economic indicator. Use of its 
derivative GDP per capita (GDPpc) for transnational benchmarking is reasonable due to existing single metric on the EU scale.

In addition the correlation between the integrated quality of life (wellbeing) indexes (World Happiness Index, Human Development Index) and GDPpc for EU countries is very strong (0.85-0.90); actually the EU member states responsibly transfer economic benefits to social sphere. Therefore we used the GDPpc as the dependent (target) variable. It should be taken into account that the DESI of the year $\mathrm{k}$ is mainly based on the component indicators of year k-1; therefore we associated the GDPpc of the year k-1 with the DESI of the year $\mathrm{k}$.

There are several multivariate analytic methods that are in principle appropriate for the investigation of cause and effect relationships between the variables and consequently for the estimation of the impact of various digitalization indicators/investments on growth.

The regression analysis, as the method at the crossroads of data mining and modelling, was chosen as the most preferable statistical modelling tool, which is directly focused on the relationships between a dependent variable and several independent variables (predictors); in our case it will show changes of the GDPpc as a result of any predictor's changes and will identify predictors that the most improve the GDPpc (see more detailed comparative analysis of various methods in (WEB, k)). The modelled GDPpcM would be defined as a multi-parameter function of the set of predictors $(\Pi)$ :

$$
\mathrm{GDPpc}_{\mathrm{M}}=\mathrm{f}(\Pi)=\mathrm{f}\left\{\mathrm{i}_{1}, \mathrm{i}_{2}, \ldots, \mathrm{i}_{\mathrm{n}}\right\}
$$

where:

$\mathrm{n}$ - number of decisive/significant predictors $\mathrm{i}$.

According to the Occam's razor principle we will start modelling by using the more simple linear regression algorithm. Our target is to expand the benchmarking model as the linear mathematical expression:

$$
\mathrm{GDPpc}_{\mathrm{M}}=\mathrm{A}+\lambda_{1} \mathrm{i}_{1}+\lambda_{2} \mathrm{i}_{2}+\ldots+\lambda_{\mathrm{n}} \mathrm{i}_{\mathrm{n}}
$$

where:

A - constant;

$\lambda$ - estimated optimal weights of predictors.

The post-modelling analysis of residuals will show purposefulness of continuation of modelling by usage of more complicated nonlinear regression algorithms to obtain stronger cause-effect relationship.

It can be predicted that it will not be achievable the model, which is completely adequate to the growth of all countries. "No model can include all of real world's complexity or the nuance of human communication" (O'Neil, 2016); digitalization actually is a very strong driver of economy, but not a single one. Conformity of the model to the real growth could serve as the quality criterion of the modelling. Consequently, achievement of the maximum correlation between the model and the dependent variable Correl (GDPpc ${ }_{\mathrm{M}}$; GDPpc) will serve as its quality criterion. 


\section{Data gathering and analysis}

There is an undeniable impact of the digitalization on economics; logical judgments prompt us that stronger or weaker direct causality exist between the digitalization aspects/indicators and GDPpc. In addition, the growing economy generates the positive feedback - increasing demand for and usage of digital services, more investments in advanced technologies; this factor strengthens the direct impact and converts the association into the bidirectional causality. Proportions of the direct and reverse components of causality for various aspects naturally are different, but independently of them cause and effect relationships between the digital indicators and GDPpc exist; consequently fig. 1a indicates quite strong correlation between the DESI and GDPpc.

One can see a data point on the scatter plot (fig. 1a) that seems to deviate markedly from other data points in the set. Using a box plot procedure we identified Luxembourg as a country with unusually high GDPpc level (fig. 1b); its data point exceeds the upper fence. The reason is confidently understandable, its GDP forms in a very specific way. Actually excellent economy of the Luxembourg is based on the off-shore banking and wide location of the EU-scale institutions and therefore does not depend on the local aspects.
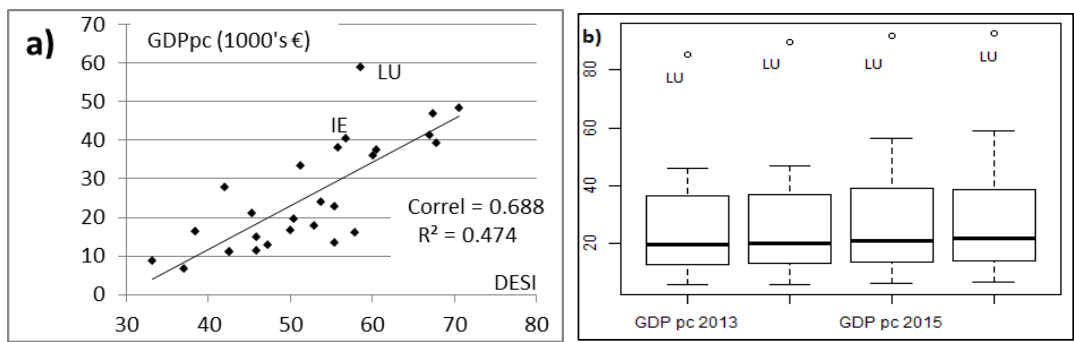

Fig. 1. Association between DESI 2017 and GDPpc 2016 (1a) and box plots of GDPpc data samples 2013-2016 (1b). Developed by authors.

Analysis of the annual data for 2013-2015 indicates a similar situation. Rejection of such data points from data set is necessary to achieve the normal observations on general EU scale processes that are based on value added, which is generated in the corresponding country: "Detected outliers are candidates for aberrant data that may otherwise adversely lead to model misspecification, biased parameter estimation and incorrect results. It is therefore important to identify them prior to modelling and analysis" (Ben-gal, 2010). Exclusion of the Luxembourg, of course, strengthened the correlation for remaining 27 countries (fig. 2a). 


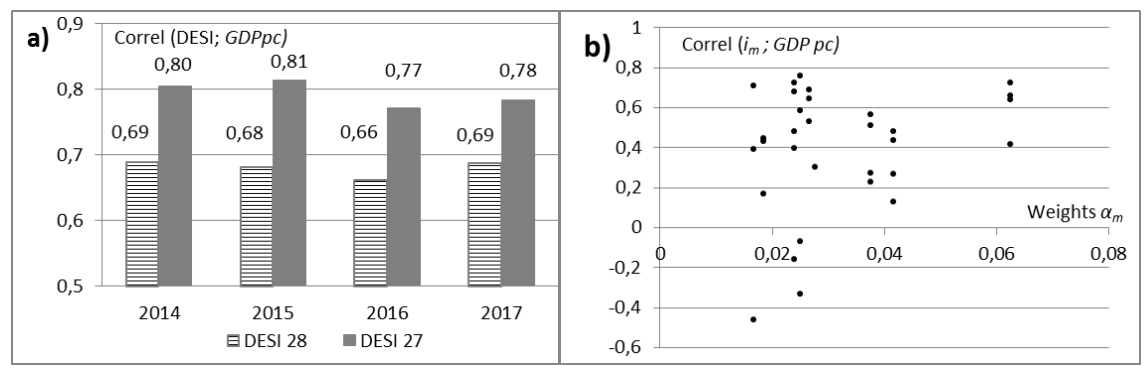

Fig 2. Correlations between DESI and GDPpc 2014-2017 for 28 and 27 EU countries (2a) and scatter plot of weights $\alpha_{\mathrm{m}}$ and (Correl $\mathrm{i}_{\mathrm{m}}$; GDPpc) for 2017 (2b). Developed by authors.

Actually Ireland's case in 2015-2016 also is very near to the upper fence. Because of the lowest tax rates across the EU countries (taxes and levies were $23.8 \%$ of GDP in 2016) Ireland has hosted the central offices of several multinational companies; all turnover of these companies since 2015 formally relates to the Ireland economy, that caused incredible growth of the Ireland's GDP by 34.7\% in 2015 against 2014. Nevertheless, formally Ireland's data point doesn't exceed the upper fence; therefore we didn't exclude Ireland from the data set.

The DESI is created by the aggregating of normalized indicators (values $0-1$ ), which is based on the experts' considerations on the weight/importance $\alpha_{\mathrm{m}}$ of each component indicator $\mathrm{i}_{\mathrm{m}}$ in the DESI score.

We calculated real correlations between the values of every indicator and GDPpc (Correl $\mathrm{i}_{\mathrm{m}}$; GDPpc). Majority of calculations show the moderate positive association (0.4-0.6). Some correlations are strong; a logical evaluation indicates a dominant direct causality (e.g., indicators $2 \mathrm{a} 1,2 \mathrm{~b} 1$; here and further we are using abbreviations from the (WEB, c)), as well as bidirectional (e.g., 3c2) and mostly reverse causality (e.g., 3a3) among them. There is also a week correlation between several popular indicators and the GDPpc (e.g., 1c2, 4a2, 5a2, 5a4). Few negative correlations (3a1, 3b1, 3b2) relate to the indicators that characterize free of charge available services, which apparently are more attractive for lower income societies. Majority of annual correlations of concrete indicator are quite stable in the time period, only some of them are strongly increasing $y-$ o-y (e.g., 2b2, 4a3, 4a5, 4b2, 4b3) or decreasing (e.g., 5a4).To assess the usability of experts' considerations in relation to economic growth, we compared two data sets above-searched correlations Correl ( $i_{m}$; GDPpc) with expert weights $\alpha_{m}$ of component indicators $i_{m}$ in the DESI (fig. 2b). One can see the week association between them.

The conclusion is obvious: both individual correlations of component indicators and their weights in the DESI do not provide reliable reflection on association of the digitalization with the GDPpc. Secondary, not all indicators are decisive for the GDP growth, as well as the association between the set of decisive predictors and the GDPpc can be improved. 


\section{Modelling}

For modelling we chose the well-developed $\mathrm{R}$ statistics language, and used the built-in linear regression model, which is called by command $\mathrm{lm}$.

Table 1. Parameters of the 31-predictor model.

\begin{tabular}{|r|r|r|}
\hline & \multicolumn{1}{|c|}{ Estimate } & p-value \\
\hline $\mathbf{1 a} 1$ & $\mathbf{1 2 . 6 7 9 9}$ & $\mathbf{0 . 0 0 2 3 5}$ \\
\hline $1 \mathrm{a} 2$ & -14.1088 & 0.00200 \\
\hline $1 \mathrm{~b} 1$ & -1.8505 & 0.70871 \\
\hline $1 \mathrm{~b} 2$ & -1.0822 & 0.76845 \\
\hline $\mathbf{1 b 3}$ & $\mathbf{7 . 7 0 2 6}$ & $\mathbf{0 . 0 2 4 5 9}$ \\
\hline $1 \mathrm{c} 1$ & 0.9375 & 0.85985 \\
\hline $1 \mathrm{c} 2$ & -5.0184 & 0.26169 \\
\hline $1 \mathrm{~d} 1$ & 3.2370 & 0.44263 \\
\hline 2a1 & $\mathbf{2 3 . 8 0 3 8}$ & $\mathbf{0 . 0 4 2 3 9}$ \\
\hline 2a2 & -23.4455 & 0.08888 \\
\hline 2b1 & $\mathbf{1 8 . 0 1 4 2}$ & $\mathbf{0 . 0 1 0 4 9}$ \\
\hline
\end{tabular}

\begin{tabular}{|r|r|r|}
\hline & \multicolumn{1}{|c|}{ Estimate } & p-value \\
\hline $2 \mathrm{~b} 2$ & 0.5714 & 0.93518 \\
\hline $3 \mathrm{a} 1$ & -16.4710 & $4.82 \mathrm{e}-05$ \\
\hline $3 \mathrm{a} 2$ & -13.5653 & 0.12131 \\
\hline $\mathbf{3 a 3}$ & $\mathbf{3 2 . 3 1 1 3}$ & $\mathbf{1 . 9 7 e - 0 7}$ \\
\hline $3 \mathrm{~b} 1$ & -8.9017 & 0.04796 \\
\hline $3 \mathrm{~b} 2$ & 7.2214 & 0.19607 \\
\hline $3 \mathrm{c} 1$ & -0.7721 & 0.92191 \\
\hline $3 \mathrm{c} 2$ & 1.5550 & 0.82446 \\
\hline $\mathbf{4 a} 1$ & $\mathbf{1 5 . 2 3 7 1}$ & $\mathbf{0 . 0 0 1 3 9}$ \\
\hline $4 \mathrm{a} 2$ & -5.5509 & 0.24597 \\
\hline $4 \mathrm{a} 3$ & 5.1128 & 0.43602 \\
\hline
\end{tabular}

\begin{tabular}{|l|r|r|}
\hline & \multicolumn{1}{|c|}{ Estimate } & p-value \\
\hline $4 \mathrm{a} 4$ & 2.9005 & 0.28336 \\
\hline 4a5 & -14.2582 & 0.13479 \\
\hline $4 \mathrm{~b} 1$ & -8.5831 & 0.23069 \\
\hline $4 \mathrm{~b} 2$ & 9.6835 & 0.12971 \\
\hline $\mathbf{4 b 3}$ & $\mathbf{2 6 . 7 2 0 1}$ & $\mathbf{0 . 0 0 1 8 9}$ \\
\hline $5 \mathrm{a} 1$ & 5.5014 & 0.11065 \\
\hline $5 \mathrm{a} 2$ & 0.7780 & 0.84544 \\
\hline $5 \mathrm{a} 3$ & -3.1895 & 0.47181 \\
\hline $5 \mathrm{a} 4$ & 3.2297 & 0.38432 \\
\hline
\end{tabular}

Residual standard error: 3.64 on 76 degrees of freedom

Multiple R-squared: 0.9469 , Adjusted R-squared: 0.9252

F-statistic: 43.71 on 31 and 76 DF; p-value: $<2.2 \mathrm{e}-16$

We have 31 predictors and the GDPpc as the target/response variable for $27 \mathrm{EU}$ economies. Direct usage of the general linear regression multi-variable modelling means, that we are searching the 31-dimension hyperplane on which 27 defined points are placed. Mathematically it means excess information (so called overfitting), various formulas can be produced, an ideal formal conformity (Correl $=1 ; \mathrm{R} 2=1$ ) characterizes all of them; nevertheless the general tendency is not reflected. Therefore to obtain the valid model we combined all data sets related to 2014-2017, i.e., modelling was based on 108 data sets containing 31 predictors. We obtained an excellent formal association $($ Correl $=0.97)$ that is very near to the perfect (see modelling figures in table 1$)$.

The modelling software provided 13 negative estimates for the model's coefficients in the outcome to achieve the highest formal correlation. It is fundamentally illogical to suppose that increasing fixed or mobile BB take-up or the usage of cloud computing could have a negative impact on economy.

The model cannot be an abstract representation of the data scope. "Models are constructed not just from data but from the choices we make about which data to pay attention to - and which to leave out. They must deliver transparency, disclosing the input data they're using as well as the results of their targeting" (WEB, k). The impact of each individual aspect on the result of the total mining of the whole data set is, of course, different from the individual correlation (e.g., due to mutual correlations of predictors). It is more likely that the impact of mentioned 13 predictors on the economy is small, and it is mathematically more advantageous to use them for the formal correction of the model to achieve higher correlation. Therefore for the further development of the model corresponding 13 predictors were excluded from the potential KPI set. 
Table 2. Parameters of the final 7-predictor model.

\begin{tabular}{|c|l|c|c|c|}
\hline & & Estimate & p-value & Signif. codes \\
\hline & Intercept & -21.730 & $7.13 \mathrm{e}-08$ & \\
\hline 1a1 & Fixed BB Coverage & 15.061 & 0.000671 & $* * *$ \\
\hline 1b3 & BB spectrum availability & 10.495 & 0.002310 & $* *$ \\
\hline 2a1 & Internet users & 4.926 & 0.506883 & \\
\hline 2b1 & ICT specialists & 17.573 & 0.015054 & $*$ \\
\hline 3a3 & Video on demand & 19.063 & 0.000136 & $* * *$ \\
\hline 4a1 & Electronic information sharing (ERP) & 9.732 & 0.036122 & $*$ \\
\hline 4b3 & SMEs selling on-line & 18.358 & 0.005184 & $* *$ \\
\hline & $\begin{array}{l}\text { Residual standard error: 6.66 on 100 degrees of } \\
\text { Multiple R-squared: 0.766, Adjusted R-squared: }\end{array}$ & 0.7497 \\
F-statistic: 46.78 on 7 and 100 DF; p-value: <2.2e-16 &
\end{tabular}

For determination of KPIs we used a typical threshold for the evaluation of predictors' significance: the probability for a null hypothesis (p-value) is less than 0.05 . Seven bolded predictors (table 1) meet this condition. Consequently we based the final step of modelling on 108 data sets containing 7 determined predictors (potential KPIs); results are presented in table 2 .

The 7-predictor model (GDPpcM on fig 3a) indicates correctness of our hypothesis; the combination of seven KPI, which impact on the response variable is decisive, provides stronger association ("Model 108" on fig. 3b) with economic growth (GDPpc) than voluntary aggregated 31 -indicator ("DESI" on fig. 3b).
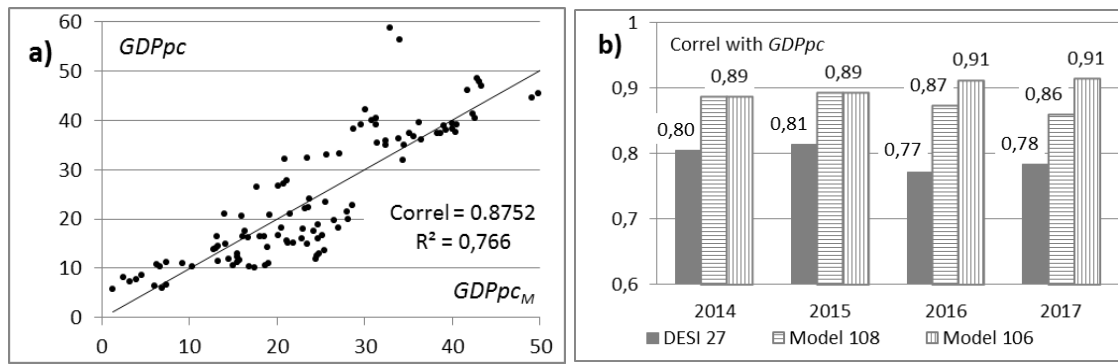

Fig. 3. 7-predictor model (3a) and increasing association between model and GDPpc for 108 and 106 used data sets (3b). Developed by authors.

To examine quality of linear regression model we used $\mathrm{R}$ diagnostic plots. It is desirable for a good model that the residuals are independent and normally distributed. The fig. 4a shows that residuals are quite equally spread around a horizontal zero line, the model meet the linearity presumption. There are no patterns between the residuals and fitted values thus the independence assumption might hold as well. The quantile- 
quantile plot (fig. 4b) approves that the standardized values of residuals are not too big (modulus is less than 2, excluding two data points) as well as that the residuals are normally distributed. Histogram on fig. $4 \mathrm{c}$ suggests the normality of the residuals around the zero value. The fig. $4 \mathrm{~d}$ confidently confirms what we have seen in figures $4 \mathrm{a}, 4 \mathrm{~b}$ and $4 \mathrm{c}$ - outlying values of mentioned two data points against a regression line; they are identified as \# 68 (Ireland 2016) and \# 95 (Ireland 2017).

After exclusion of both data points, calculations, which are based on 106 data sets, shows that points \#68 and \#95 really are influential (see "Model 106" on fig. 3b), the correlation for all years reaches 0.9. Nevertheless both data points are inside the Cook's distance (although very close to the threshold), and we formally cannot exclude them from the analysis.
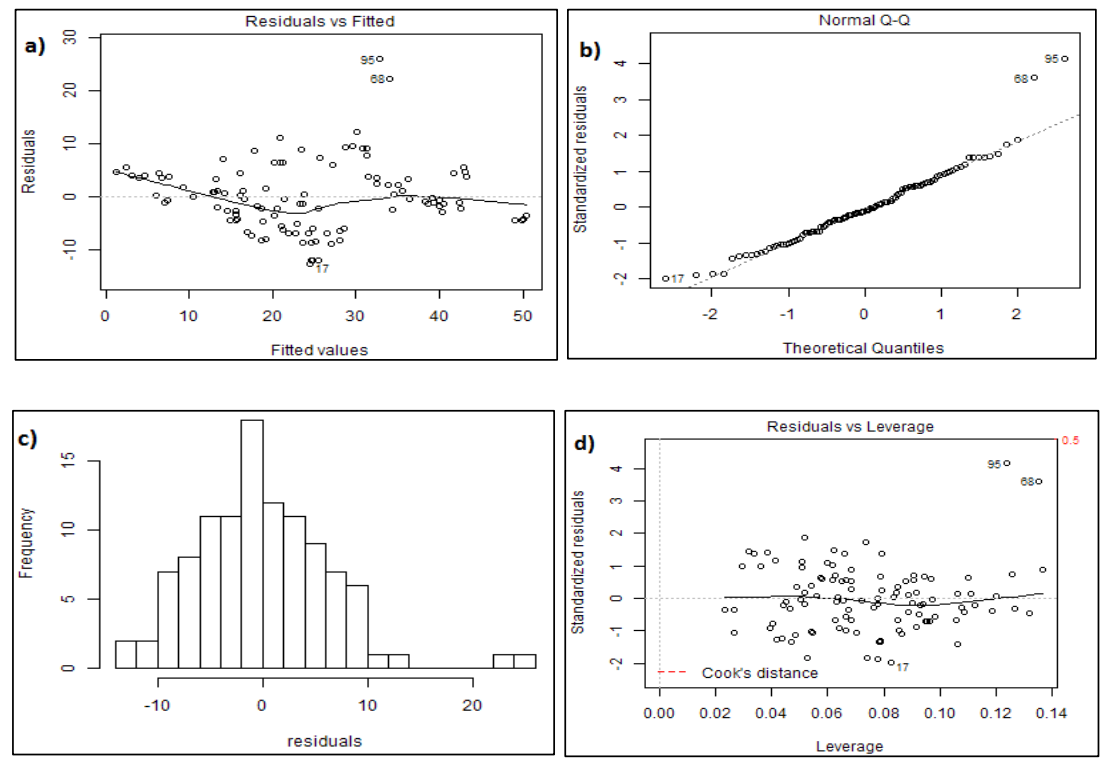

Fig. 4. Residual characteristics of the fitted model. Developed by authors

Actually we have achieved the stated objectives of the study using the linear regression tool; to continue modelling, using some nonlinear regression algorithm, is not purposeful because of the existing gaps and corresponding approximations in the input data set.

\section{Analysis and Baltic case}

\subsection{Connectivity}

The connectivity to BB should be evaluated as very valuable digital driver of economic growth.

There is a different significance of accessibility to fixed and mobile BB. Our model recognized fixed $\mathrm{BB}$ as more significant technology (compare characteristics of predictors $1 \mathrm{a} 1$ and $1 \mathrm{~b} 3$ in tables). Despite the $\mathrm{y}-\mathrm{O}-\mathrm{y}$ increase of the mobile data traffic, 
the global mobile traffic was only 7 percent of the total IP traffic in 2016 (WEB, a). The weather and surface stability problems, differences between indoors and outdoors coverage, so called cell breathing and not guaranteed bandwidth remain the serious braking factors for mobile business applications; reliability and consistency of connectivity is an important issue for all customers (Webb, 2013).

The mobile BB has a greater positive economic impact in low income economies than in developed EU countries (Thompson et al., 2011). It can temporarily fill in gaps in the fixed BB coverage in sparsely populated (rural) areas (Prieger, 2013) that is a current case for Baltic countries too. Nevertheless the significance of mobile BB will increase in near future due to the development of unmanned mobile objects - robots, cars, drones, etc.

The next natural question is: how the speeds of connections impact the economic development? The modelling algorithm selected the standard fixed BB coverage and BB spectrum availability as the KPI; it clearly approves conclusions of several analytical reports: the very fast BB really is busines's tomorrow.
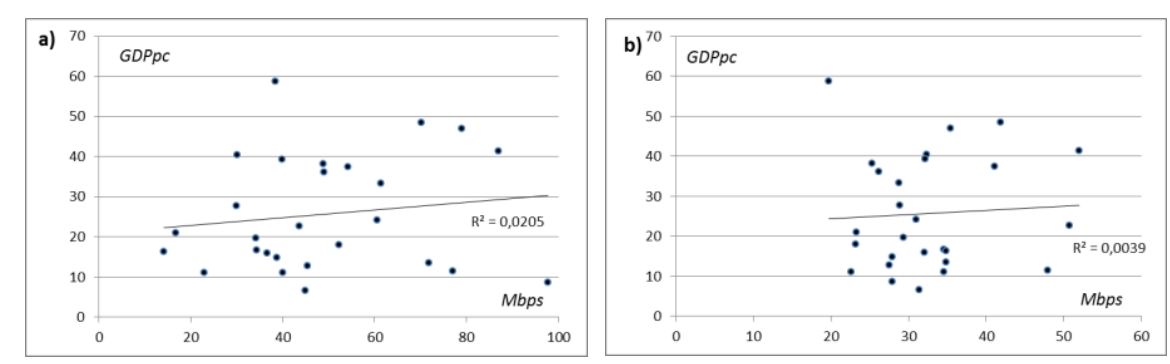

Fig. 5. Association between GDPpc and BB download speed in EU countries, October 2017; (5a) - fixed BB, (5b) - mobile BB. Developed by authors.

Association between the GDPpc and BB download speed (WEB, 1) in the EU countries is very week (fig. 5). The resume of Ericson's study (WEB, k) is understandable: increase of the speed from narrow band $128 \mathrm{kbps}$ till $1 \mathrm{Mbps}$ produces productivity gain of $11.1 \%$ (and consequently economic growth), while further increase from $1 \mathrm{Mbps}$ till $10 \mathrm{Mbps}$ (not speaking about $100 \mathrm{Mbps}$ ) indicates only insignificant impact on productivity. Forbes also concludes similarly: "National broadband is a much better investment than fast broadband. Getting everyone, however rural, up to $2 \mathrm{Mbit}$ produces a much better return on investment than trying to make sure that urban areas have 50 Mbit, or 100" (Worstall, 2012). Actually any speed in the range currently is sufficient for the business transactions; only $10 \%$ of enterprises in the EU are analysing big data and $22 \%$ of enterprises are using the cloud computing services (2016). Lithuanian and Estonian entrepreneurs are around the mean EU28 level in these aspects while Latvian business is lagging behind.

The rural BB coverage remains the basic connectivity problem for Baltic States, only Lithuania has exceeded the mean EU28 level due implemented publicly funded RAIN projects in sparsely populated areas, which definitely would not be covered by the 
private operators. The roll-out of similar middle-mile networks is going on in Estonia (EstWin project) and Latvia ("Development of next generation electronic communications networks in rural areas"). The Government of Estonia has announced also $20 \mathrm{M} €$ subsidies for the last-mile connections in areas where distances between users are great.

The strategy of Baltic States was based on investments in fiber coverage instead of the development of DSL wired networks. Today it can be evaluated as a forward looking decision, the significant impact of very fast BB on economic growth will appear in the future (as well as full return on investments) due to the gradual wide implementation of advanced technologies (e.g., big data mining, artificial intelligence, etc.).

Because radio spectrum is a finite resource, availability of spectrum is a principal issue for business to develop the wireless broadband electronic communication services and applications (including WiMax networks and WiFi hotspots). The mathematical selection of spectrum availability as KPI related to the mobile BB accessibility approves the EU approach: the spectrum policy is one of the digital market pillars.

Baltic States are well situated (Latvia - 3rd rank among EU countries, Lithuania 5th, Estonia -7 th rank in 2017) in relation to assignment of harmonized spectrum bands. Unsolved cross-border coordination issues with non-EU countries related to the 700 MHz band create the single real problem for Baltic States at least until 2022.

\subsection{Human capital}

Inclusion of the indicator $2 \mathrm{~b} 1$ (ICT specialists) in the scope of KPI clearly indicates that a lot of skilled ICT workers are necessary for economic growth.

The deficiency of ICT workforce as a pan-European problem (the model of 2017 identified shortage of 500000 ICT experts by 2020 (WEB, d); different ICT employment in EU countries (1.2\%-6.5\% of total employment) is only one side of the medal.

Another objective peculiarity is an easy option of remote work (e.g., shared service centers, private contracts) for the ICT experts, which generates the increasing crossborder demand for specialists from countries of lower earnings, including Baltic States. Excellent BB connectivity and arranged business environment in Baltics is additional driver of the process. The result is:

- sharply increasing labour costs in the ICT sector in comparison with the general level in low-cost countries $(<20 € /$ hour, see fig. 6a); it makes harder employment of the ICT specialists in low-profit enterprises;

- entry of not-high-skilled people without a formal degree (e.g., self-educated people, college level students, professionals from related (mostly STEM) sectors) in the ICT sector; it decrease the general skills level and productivity in the sector (e.g., the productivity in the sector decreased by $17 \%$ from 2012 to 2016 in Latvia).

The local business is the first and the main looser; it concerns Baltic States to the full extent. The demand for specialists exceeds their supply; e.g. there is fivefold gap in Lithuania. It fully relates to the e-leadership skills too, which combine a high level of IT skills and significant business experience. Only in Estonia the quantity of skilled ICT workers is above the EU28 mean level. The ICT workers' employment in enterprises is lower than the EU average, and it is harder-to-find specialists (fig. 6b). Of course, it has a braking effect on the economy. 


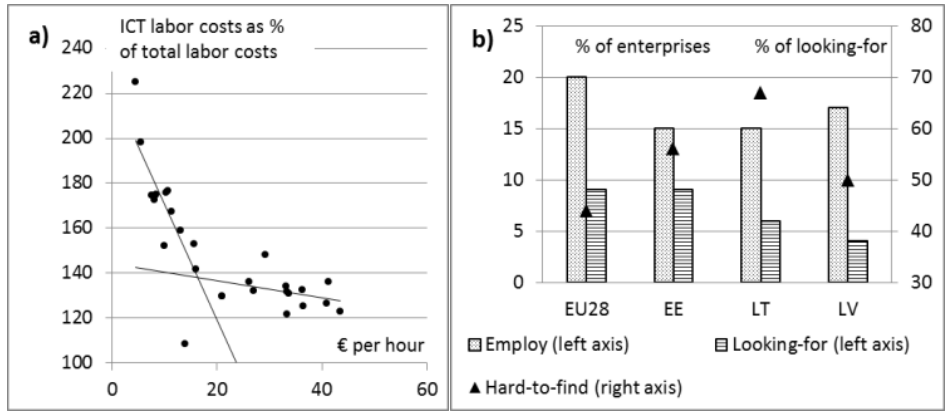

Fig. 6. ICT specialists (2016); labor costs (6a) and shortage in enterprises (6b). Source: Eurostat; developed by authors.

The capacity of the educational systems currently is insufficient - only 359 bachelors graduated ICT studies in Estonia, 364 in Latvia, 442 in Lithuania in 2015. Governments are planning to attract foreigners on both student and professional levels; e.g., Estonian government's plans to attract in 2018 no less than 500 specialists in the ICT field; Latvia has approved necessary normative environment for terminated high-level experts immigration.

In addition to presence of ICT specialists, general digital literacy level of employees also provides the strong positive impact on economy. There is stable and extremely strong mutual correlation between another KPI of this subdivision 2a1 (Internet users) and 2a2 (Basic or above basic digital skills) in 2014-2017 (0.93-0.95), that is fully understandable. The digital literacy is necessary not only for private Internet usage, it has become a requisite for the most of professions; $67 \%$ of the EU employees need more than basic ICT skills to do their job (WEB, f).

In the Baltic States, for a long time, various public and private educational activities have been set up for raising the digital literacy for different groups of people, from the elementary school curriculum to the specialized courses for specialists, seniors, etc. groups. Nonetheless, the overall level is still not satisfactory.

\subsection{Integration of digital technology}

The dimension includes several e-business related indicators; our model selected two of them as the KPI.

The indicator $4 \mathrm{~b} 3$ (proportion of SMEs that are selling on-line cross-border) is classified as the most significant indicator of this dimension. There is a natural and very strong mutual correlation between $4 \mathrm{~b} 1$ (proportion of SMEs that are selling on-line) and 4 b3 (0.8 in 2016-2017), actually exactly the selling on-line is the decisive factor. One more very close statistical indicator - proportion of enterprises receiving orders via computer networks - actually accents necessity to implement some system for entry and processing of sales orders as the first step in development of full-scale e-business. Association between these indicators (fig. 7a) is extremely strong (Correl $=0.943$ in 2017); the difference of only 1-3 percentage points between both indicators is typical for 
the EU countries. In total one can see strong positive impact of digitalization (optimization) of business transactions between enterprises.

Fig. 7a separates three leaders in this field (Sweden, Denmark and Ireland), all of them are among top European economies. Lithuania is ranked well above EU28 level, Estonia slightly below, nevertheless both of them in the large group of moderate countries. Latvia currently is less successful.

The selection of another KPI $4 \mathrm{a} 1$ (proportion of enterprises that have implemented electronic information sharing (ERP)) points how significant is to digitize the management of internal business processes. Although the ERP is a stand-alone tool, by complex usage with another tool - customer relationship management (CRM) system its potential can be best realized to provide the increasing efficiency and scale of the business. In any case the entrepreneurs are convinced of the usefulness of introduction of both tools, association between usage of them is strong - 0.73 in 2017 (fig. 7b). Once more, the leaders (Belgium, the Netherlands and Germany) are among top economies.
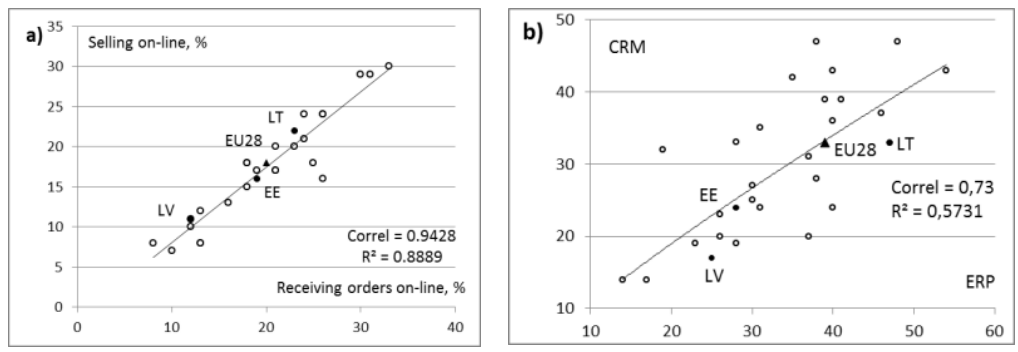

Fig. 7. E-business indicators (2017); percentage of enterprises receiving orders and selling online (7a) and using ERP and CRM software (7b). Source: Eurostat; developed by authors.

The business philosophy is different in the EU Member States (mutual correlation between the internal indicator $4 \mathrm{a} 1$ and external indicator $4 \mathrm{~b} 3$ is only 0.40 in 2017). Even the leading EU economies have not yet fully benefited of digitalization of business processes.

Lithuanian business can be evaluated as successful not only in Baltic scale, while Estonia is slightly and Latvia well below the EU28 mean level. It can be evaluated as the significant braking factor for competitiveness of economies and their sustainable growth.

\subsection{Others}

The causality between the indicator $3 a 3$ (use of video-on-demand) and the GDPpc is fundamentally different from those analyzed above.

A reverse causality is the primary one in this case: it indicates strongly growing interest of consumers to use the service due increasing material welfare level of society, i.e. growth of GDP. There is lack of reliable statistics on the VoD revenues on the EU and country level, especially it relates to Baltics; some official information can be found in $(\mathrm{WEB}, \mathrm{j})$. Due to the increase of both penetration and the ARPU (average revenue per user), annual growth rate of $\mathrm{VoD}$ revenues is assessed on level 5-8\% that is well above the GDP growth rate. 
On the other hand $\mathrm{VoD}$ market provides only a marginal direct contribution to the economic growth. In neighbor countries (Finland, Sweden, Poland, Hungary) the VoD market was below $0.01 \%$ of GDP in 2012; there is no reason to evaluate the VoD market in Baltics as much more significant GDP share even today.

It is impossible to determine exactly the proportion of direct and reverse components; in any case the reverse part of causality definitely is the decisive one. In addition, it should be emphasized that all above-mentioned aspects of digitalization affect the GDP by improvement of the functioning of various sectors, while the VoD market doesn't affect other branches.

The impact of digital public services on economic growth is insignificant that is understandable. Their major contribution relates to the governance and public services.

\section{Conclusions and recommendations}

The created 7-KPI based benchmarking model well reflects the association of digitalization aspects (BB connectivity, digital skills, e-business environment) with the growth of EU economies. The performed analysis and the model indicate the key digital drivers of EU economies. The model quantitatively confirms several popular qualitative judgments about the importance of some digital aspects for the economic growth (e.g., the presence of ICT specialists, the transformation of business transactions into a network environment), but not all of them (e.g., it is not necessary for business to increase the speed of BB connection above some certain limit). The model indicates that investments in the factors, which relate to the dimensions Use of Internet and Digital public services, marginally contribute to the economic growth.

The simplicity of proposed model is its strong advantage for the practical applications. Despite of the usage of seven predictors only, the correlation between the model and the GDPpc is very strong (around 0.9 in 2013-2016). The selection of digitalization aspects with the most significant impact on the economic growth should be evaluated as the major benefit of the study; any economy would use these results for the sustainable planning and assessment of investments and activities in various aspects of digitalization.

All observations of the model's analysis strongly relate to the Baltic States, which currently are not among the leading EU economies yet; the model clearly shows the digital weaknesses, the prevention of which would make the most effective contribution to the GDP growth.

Very good supply of the BB connectivity is one of the key strengths of Baltic States; the rural coverage currently is the single remaining connectivity problem. Roll-out of the last-mile consumer lines in rural areas, where distances between users are great, will be a tomorrow's challenge for governments. At the same time the very high speed NGA networks in Baltics are well prepared for the future growing demand.

The electronic communications regulators in Baltic States are hardly working to assign the harmonized BB spectrum bands. More active EU support to solve $700 \mathrm{MHz}$ transnational problems would be necessary. 
There is an insufficient availability of the ICT expertise in Baltic's labour market; both options to increase the number of ICT specialists should be exploited immediately improvement of capacity of the educational systems as well as attraction of foreigners. The public and private educational activities should be continued and even expanded to increase the general digital literacy; e.g., inclusion of IT courses in curriculum of all study programs (in the STEM programs first of all) would be useful.

Organization of training process for businessmen on digitalization of internal and external business processes and transactions seems to be a single real activity during 2018-2020, when the stable economic growth is forecasted for Baltic States.

\section{References}

Ben-gal, I. (2010). Outlier detection. In Maimon, O., Rokach, L., (Eds); Data Mining and Knowledge Discovery Handbook, pp 117-130. Springer, Heidelberg.

Bicevskis, J., Cerina-Berzina, J., Karnitis E., Karnitis, G. (2014). Transparent Model for State Management. In Anthopoulos, L. G., Reddick, C. G. (Eds.) Government E-strategic Planning and Management, pp. 83-103. Springer, Heidelberg.

Ghosh, S. (2017). Broadband Penetration and Economic Growth: do Policies Matter? Telematics and Informatics. 34(5), 676-693

Goldfarb, A., Tucker, C. (2017). Digital Economics. National Bureau of Economic Research, Working Paper 23684, 2017. http://www.nber.org/papers/w23684

Haqqani A. B. (Ed). (2005). ICT Development Indices. In: The Role of Information and Communication Technologies in Global Development - Analyses and Policy Recommendations. United Nations ICT Task Force Series (book 3), pp. 285-331. UN, New York

Karnitis, G., Karnitis, E. (2017). Sustainable Growth of EU Economies and Baltic Context: Characteristics and Modelling. J. Int. Studies. 10(1), 209-224.

Knickrehm, M., Berthon B., Daugherty P. (2016). Digital Disruption: the Growth Multiplier, https://www.accenture.com/t00010101T000000__w_/br-pt/_acnmedia/PDF-14/AccentureStrategy-Digital-Disruption-Growth-Multiplier-Brazil.pdf

O’Neil, C. (2016). Weapons of Math Destruction; How Big Data Increases Inequality and Threatens Democracy. Crown, New York.

Prieger, J. E. (2013). The Broadband Digital Divide and the Economic Benefits of Mobile Broadband for Rural Areas. Telecom. Pol. 37(6-7), 483-502.

Quiggin, J. (2014). National Accounting and the Digital Economy. Econ. Anal. \& Pol. 44(2), 136142.

Sarma, U., Bazbauers, G. (2017). District Heating Tariff Component Analysis for Tariff Benchmarking Model. Energy Proc. 113, 104-110.

Thompson, H. G. Jr., Garbacz, C. (2011). Economic Impacts of Mobile versus Fixed Broadband. Telecom. Pol. 35(11), 999-1009.

Wallace, N., Castro, D. (2017). The State of Data Innovation in the EU. Center for Data Innovation. http://www2.datainnovation.org/2017-data-innovation-eu.pdf

Wammerdam, M. (2014). Charting the Digital Economy. http://www.themetisfiles.com/ 2014/06/charting-the-digital-economy/

Webb, W. (2013). Prefer consistent connectivity to erratic high speed. http://www.webbsearch.co.uk/wp-content/uploads/2013/09/Connectivity-not-speedextended-version-1.pdf

Worstall, T. (2012). Does High Speed Broadband Increase Economic Growth? https://www.forbes.com/sites/timworstall/2012/08/26/does-high-speed-broadband-increaseeconomic-growth/\#41726aa33966 
Zuters, J., Valeinis, J., Karnitis, G., Karnitis, E. (2016). Modelling of Adequate Costs of Utilities Services. In Dregvaite, G., Damasevicius, R. (Eds) ICIST 2016; Information and Software Technologies, pp. 3-17. Springer, Heidelberg.

WEB (a) Cisco Visual Networking Index: Forecast and methodology, 2016/2021. https://www.cisco.com/c/en/us/solutions/collateral/service-provider/visual-networkingindex-vni/mobile-white-paper-c11-520862.html

WEB (b) Digital economy and society. https://europa.eu/european-union/topics/digital-economysociety_en

WEB (c) Digital Economy and Society Index. https://ec.europa.eu/digital-single-market/en/desi

WEB (d) High-Tech Leadership Skills for Europe - towards an Agenda for 2020 and Beyond. http://eskills-scale.eu/fileadmin/eskills_scale/all_final_deliverables/scale_eleadership_agenda_final.pdf

WEB (e) ICT Development Index 2017. https://www.itu.int/net4/ITU-D/idi/2017/index.html

WEB (f) Matching Skills and Jobs in Europe. http://www.cedefop.europa.eu/en/publications-andresources/publications/8088

WEB (g) Mid-Term Review on the Implementation of the Digital Single Market Strategy. COM (2017) 228 final. https://ec.europa.eu/transparency/regdoc/rep/1/2017/EN/COM-2017-228F1-EN-MAIN-PART-1.PDF

WEB (h) Monitoring the Digital Economy and Society 2016-2021. EC DG Communications Networks, Content \& Technology, 2015. http://ec.europa.eu/eurostat/documents/ 341889/725524/Monitoring+the+Digital+Economy+\%26+Society+2016-2021/7df02d85698a-4a87-a6b1-7994df7fbeb7

WEB (i) OECD Digital Economy Outlook 2017, OECD Publishing, Paris. http://dx.doi.org/10.1787/9789264276284-en

WEB (j) On-Demand Audiovisual Markets in the European Union. European Commission. http://ec.europa.eu/information_society/newsroom/cf/dae/document.cfm?doc_id=6352

WEB (k) Socioeconomic Effects of Broadband Speed. http://nova.ilsole24ore.com/wordpress/wpcontent/uploads/2014/02/Ericsson.pdf

WEB (1) Speedtest global index; October 2017. http://www.speedtest.net/global-index

\section{Authors' information}

Girts Karnitis: Professor at the Faculty of Computing, University of Latvia

Andris Virtmanis: Associated Professor at the Faculty of Electronics and Telecommunications, Riga Technical University. Director of the Electronic Communications and Post Department, Public Utilities Commission of Latvia

Edvins Karnitis: Professor, Leading Researcher at the Faculty of Computing, University of Latvia. Adviser at the Cross-sectoral Coordination Centre of the Republic of Latvia. 